\title{
STRATEGIC OUTSOURCING: EVIDENCE FROM BRITISH COMPANIES
}

Marketing Intelligence and Planning, (2000) 18:4, 213-219

\author{
YING FAN \\ Lincoln School of Management \\ Brayford Pool \\ Lincoln, LN6 7LS \\ Tel 01522-886345 \\ Fax 01522-886023 \\ email yfan@lincoln.ac.uk
}




\title{
STRATEGIC OUTSOURCING: EVIDENCE FROM BRITISH COMPANIES
}

\begin{abstract}
Outsourcing has become an increasingly popular option for many organisations. But they vary in terms of activities being outsourced, reasons for and benefits from outsourcing, and how the decision was made. This article presents an empirical research on fourteen companies. It found out, a) in most cases it was the 'peripheral' support activity being outsourced with cost reduction as the primary driver; b) outsourcing decision was being made early in the process without active involvement of the in-house provider; and c) there were problems in supplier selection and management. The research identified preoutsourcing decision process and post-outsourcing management as the two key areas that gave cause for concern, and offered recommendations for improvement.
\end{abstract}

KEY WORDS: outsourcing, decision making, supplier management, British companies. 1

\footnotetext{
${ }^{1}$ This paper was based on the MBA Dissertation by Clive Millington, University of Hertfordshire.
} 


\section{STRATEGIC OUTSOURCING: EVIDENCE FROM BRITISH COMPANIES}

\section{$\underline{\text { INTRODUCTION }}$}

Outsourcing is a contractual agreement between the customer and one or more suppliers to provide services or processes that the customer is currently providing internally. The fundamental difference between outsourcing and any other purchasing agreement is that the customer contracts-out a part of their existing internal activity. There are many reasons why a company may choose to outsource and rarely will it be for one single reason. While they are normally specific to the particular situation, some commonly-cited reasons are:

- to reduce cost

- to improve quality, service and delivery

- to improve organisational focus

- to increase flexibility

- to facilitate change.

The use of outsourcing has seen phenomenal growth in the past few years. For example, 25\% of all IT activities in the UK was being outsourced in 1996 compared with only 15\% in 1993 (Kavanagh, 1997). Whilst the market size in the UK is not clear, the market in the US is estimated in 1996 by the Institute of Outsourcing at \$100bn (Brown, 1997). A survey of outsourcing market by PA Consulting Group (1996) concludes:

A progressively larger part of most businesses have been outsourced over the last five years. Projections suggest that this trend will continue, with growth set to rise a further $46 \%$ by the year 2000.

The same survey also found out that while few companies regret about outsourcing ventures, most had not met their expectations. Mediocre outcomes were frequent and real failure too common. So why so few organisations realising their outsourcing objectives? 
Clearly the outsourcer may have had unrealistic expectations, but it is more likely that the outsourcing process itself is responsible. It is on this premise that the research was conducted which aimed at exploring two specific areas: pre-outsourcing cost analysis and post-outsourcing supplier management. The first topic was chosen primarily because the existing literature is rather prescriptive and only offers transaction cost theory (Walker and Weber, 1984; Alexander and Young, 1996a) as an analytical tool, which most commentators believe is ineffective. The second topic was selected due to the lack of research on the subject, and the evidence suggested that most outsourcing deals have fallen short of expectations and deteriorated over time (Lacity, et al., 1994; Greenberg and Canzoneri, 1997). It should be noted however, that these two selected areas will not guarantee outsourcing success on their own as the subject is extremely complex with many interrelated factors, but a good understanding of them is crucial for any outsourcing decisions.

\section{THE RESEARCH}

A research was undertaken to study the company's view on outsourcing, activities being outsourced, reasons for and benefits from outsourcing and the decision process. The main objective of the research was to explore the two key areas in the outsourcing process, namely: 1) pre-outsourcing decision process; and 2) post-outsourcing supplier management. The research was conducted in two phases. The first involved a convenience survey by using postal questionnaires. The results from this survey were then analysed and suitable candidates selected to take part in the second phase, a series of face to face interviews. The target respondents were managing directors, senior managers 
or purchasing managers, who had a significant degree of influence on outsourcing decisions. 14 companies were studied with turnover from $£ 4.5$ million to $£ 30$ billion and in different industrial sectors:

\begin{tabular}{|c|c|c|}
\hline Number of organisations mailed & \multicolumn{2}{|l|}{22} \\
\hline Number of returned questionnaires & \multicolumn{2}{|l|}{14} \\
\hline Response rate & \multicolumn{2}{|l|}{$64 \%$} \\
\hline Breakdown by industry sector & $\begin{array}{l}\text { Service } \\
\text { Electronics } \\
\text { Financial services } \\
\text { Retailer }\end{array}$ & $\begin{array}{l}5 \\
6 \\
2 \\
1\end{array}$ \\
\hline Agreed to be interviewed & 10 & \\
\hline
\end{tabular}

\section{FINDINGS FROM THE SURVEY}

The questionnaire asked a broad spectrum of questions and its purpose was to understand the general outsourcing conditions in the organisation. It also asked for a specific example to be cited, for which a number of questions were asked relating to performance assessment. The main findings are reported in this section.

\begin{tabular}{|l|l|}
\hline Which statement best describes the company view on outsourcing? & Percentage \\
\hline All activities and processes are possible candidates for outsourcing & 21 \\
\hline $\begin{array}{l}\text { All activities and processes including those that form part of the } \\
\text { company's competitive advantage but excluding core competencies } \\
\text { are possible candidates }\end{array}$ & 21 \\
\hline $\begin{array}{l}\text { All activities and processes except core competencies and those that form } \\
\text { part of the company's competitive advantages are possible candidate }\end{array}$ & 57 \\
\hline
\end{tabular}


The responses indicate that most outsourced activities are 'peripheral' in nature and concurs with other research. Perhaps the most surprising finding is that three companies considered all activities as potential outsourcing candidates.

\begin{tabular}{|l|l|l|l|}
\hline Which statement best describe why you outsource ? & Agree & Neutral & Disagree \\
\hline We outsource to reduce our cost base & 29 & 14 & 36 \\
\hline We outsource where others can do it better & 57 & 21 & 7 \\
\hline We outsource to focus on our core business & 21 & 36 & 29 \\
\hline
\end{tabular}

Reasons are diverse and complex, but many considered it a venture to improve operational performance.

\begin{tabular}{|l|l|}
\hline Which statement best describes the company policy on outsourcing? & Percentage \\
\hline Outsourcing is a fully integrated part of our business planning process & 0 \\
\hline $\begin{array}{l}\text { Outsourcing decisions are in the main conducted at group board level to } \\
\text { consider its overall effect on the business }\end{array}$ & 21 \\
\hline $\begin{array}{l}\text { Outsourcing decisions are by and large conducted at divisional or } \\
\text { business unit level to consider its effect on the division or business unit }\end{array}$ & 50 \\
\hline $\begin{array}{l}\text { Outsourcing decisions are by and large made in a piecemeal fashion to } \\
\text { address particular problems or issue arising }\end{array}$ & 21 \\
\hline
\end{tabular}

This question was designed to explore to what extent decisions are forming part of the business strategy. The findings suggest that they have yet to gravitate to the top of the organisations in all but a few cases. There was also no direct correlation between business size in the $21 \%$ of respondents who were considering outsourcing proposals at board level. The findings could either suggest that as the largest percentage of outsourced activities were 'peripheral', they do not warrant board level attention. Conversely it could 
suggest that few outsourcing proposals of any nature are being considered at board level. This is covered in more detail in the interviews.

\begin{tabular}{|l|l|}
\hline $\begin{array}{l}\text { In general, is the emphasis on outsourcing business functions } \\
\text { or process? }\end{array}$ & Percentage \\
\hline Functions & 43 \\
\hline Processes & 29 \\
\hline Both & 29 \\
\hline
\end{tabular}

There is a correlation here with the opening question. Having established that peripheral activities are still predominantly outsourced it is reasonable, therefore, that these are more likely to be functional in nature. Those respondents that would consider outsourcing core competencies and activities were also, in general, outsourcing processes or both.

\begin{tabular}{|l|l|}
\hline Is there a trend in your company towards outsourcing more? & Percentage \\
\hline Yes & 86 \\
\hline No & 14 \\
\hline
\end{tabular}

In a later question, which asked whether on balance had the outsourcing of a named activity been a successful one, the only organisation that responded with a no, also answered no to this question. On balance, the majority of respondents seemed to be satisfied with outsourcing and intended to extend it. The seven remaining questions asked for a particular outsourced activity to be named and were designed to explore why they had been selected, what were the resulting benefits, and what would be done differently, if anything based on the experience. It was also designed to explore whether it had been successful and how the success was measured. 


\begin{tabular}{|l|l|}
\hline Major reasons for outsourcing a particular activity & Percentage \\
\hline Cost reduction & 64 \\
\hline Focus on core competencies & 36 \\
\hline Quality (either product or service related) & 29 \\
\hline Lack internal skills or expertise & 29 \\
\hline Entry barriers (capital equipment, technology, etc.) & 29 \\
\hline Capacity & 7 \\
\hline
\end{tabular}

Cost reduction is still the primary driver, which contradicts the PA Consulting Group survey (1996) which cited the 'search for more effective business performance' as the main reason. However it concurs with a wealth of other literature (Bettis et al., 1992) which suggests that most outsourcing deals are tactical in nature and driven by a desire to reduce cost and/or offload problem areas of their business. It is interesting to compare this table with the following one which shows the responses to the issue of benefits resulting from outsourcing a specific activity:

\begin{tabular}{|l|l|}
\hline Benefits from outsourcing & Percentage \\
\hline Cost reduction & 64 \\
\hline Freed up internal resource & 36 \\
\hline Service level improvement & 29 \\
\hline Quality improvement & 14 \\
\hline Flexibility & 7 \\
\hline
\end{tabular}

There was a direct correlation between those that sought cost reductions and those that realised them. It was also interesting that increased flexibility was very low on the list of benefits. When asked what were the major risks and issues faced, the predominant 
concern was quality (64\%), of either product supplied or general service levels. Other concerns were failure to deliver against expectations (36\%), implementation (29\%), potential job losses (21\%) and contractual issues relating to specification and accurate supplier measurement (21\%). Perhaps the most surprising omission was 'loss of control' which is widely referred to in the literature but was not evident in this survey. Perhaps this is explained through the overall satisfaction with the outsourcing ventures displayed by the respondents.

\begin{tabular}{|l|l|}
\hline What you would do differently in light of the experience? & Percentage \\
\hline Improve supplier selection process & 43 \\
\hline Improve specifications/project management & 29 \\
\hline Improve supplier reporting & 14 \\
\hline Do it earlier & 14 \\
\hline Impose stricter penalties for late delivery & 7 \\
\hline
\end{tabular}

The majority of responses related to supplier selection and management issues. The final question asked how the outsourced operation was being measured. Once again these responses were particularly interesting as in only a few instances was an ongoing program in place which monitored and set targets to drive cost down and improve the qualitative issue upwards. Some had no clear measures in place and others were contented with achieving budget targets. Only in a very few cases were customer satisfaction programs in place post-outsourcing.

\begin{tabular}{|l|l|}
\hline Supplier measurement & Percentage \\
\hline Achieved budget targets & 36 \\
\hline
\end{tabular}




\begin{tabular}{|l|l|}
\hline Clear performance measurement in place & 29 \\
\hline No clear measurement & 21 \\
\hline Not applicable / did not comment & 14 \\
\hline
\end{tabular}

\section{$\underline{\text { SUMMARY OF SURVEY FINDINGS }}$}

The results from the questionnaire were in themselves enlightening. Many of the findings agreed with the PA consulting survey (1996). The emphasis was clearly on cost driven outsourcing of peripheral activities. But general satisfaction levels were high which contradicted the PA findings. This is perhaps explained by an element of protectionism that may have crept in, as in many cases it was the outsourcing decisionmakers who completed the questionnaire. Whilst there was some evidence of outsourcing decisions gravitating towards the centre of the organisation, most outsourced were support activities and decisions were not made at the board level. On the issue of supplier selection the problem areas related to clearly defined specifications and more effective project management. Post-outsourcing measurement was centred around meeting budget targets and only in a very small percentage of the sample were they extending the measurement process further with target setting and customer satisfaction surveys. These two areas were explored in detail in the interviews. 


\section{THE INTERVIEWS}

Candidates for the second phase interviews were selected based on the following criteria, a) evidence of outsourcing in action; b) evidence of activities being outsourced that directly influence the firm's competitiveness; c) availability for interview. In total six organisations were interviewed and all interviews lasted approximately one hour. A list of questions was developed that focused on the two key success factors identified. The first four questions were concerned with the pre-outsourcing decision process while the remaining five focusing on post-outsourcing management. The questions are:

1. How was the decision on outsourcing being made?

2. To what extent was the in-house provider involved in the decision process?

3. Was the in-house provider given an opportunity to take part in the tendering process?

4. How was cost calculation performed?

5. How is the outsourced activity measured?

6. Is there a formal, ongoing measurement process?

7. How targets are set?

8. Is supplier benchmarking an ongoing process?

9. Was the in-house function given the same measures and targets?

\section{Pre-outsourcing Decision Process}

The first set of questions reviewed the reasons for selecting the particular outsourcing candidate and the stages in the decision process. In every single case, the overwhelming response related to cost, either through a belief that the internal resource was no longer competitive in the face of changing demands, or through capital investment restriction or capacity limitations. In two cases, lack of internal expertise was cited. Rather than developing these resources, it was felt that it would be cheaper to buy in skills. All in all cost was the primary driver with other more secondary benefits including, a belief that competitive advantage may be attained, increased operational efficiency and the ability 
to focus on core business. One company was actively using outsourcing as a change mechanism through initially contracting out and then re-ingesting that activity after a period of time. The rationale was that it would have been impossible to effect the service improvement and cost reduction if it had merely been implemented round the existing structure. The process of outsourcing and then retaining was seen as the most effective way of achieving major change.

When interviewees were asked to describe the stages that took place in the outsourcing decision process, a consistent pattern emerged: a) the decision was made to outsource, then a tender document was issued; and b) quotations were collated and a particular provider was selected. The most interesting observation from this was the fact that in the most cases the decision to outsource had been made prior to starting this process. While this may appear obvious it does bring into question the degree of objectivity employed. Three particularly interesting responses are provided below.

- We believe that outsourcing ... was necessary and the in-house function was not capable of delivering. Outsourcing was the only option.

- Even if the in-house function had offered the most competitive overall solution it is unlikely that we would have retained the activity. We would have re-negotiated with the supplier until their solution was the most competitive.

- The business case substantiated the decision to outsource, the process employed was designed to display this decision in the best possible light.

While a number of those interviewed displayed some degree of objectivity in the decision process, an equal amount either implicitly or explicitly stated that the decision to outsource had been made prior to the business justification. This represents the first finding in the interviews: 
In some cases the decision to outsource is being made very early in the process, and the business case is only serving to endorse the decision that by and large has already been made.

This is in incongruity with the traditional outsourcing theory (see Quinn, et al, 1994). It may also suggest a degree of outsourcing 'problems' which are not recommended. Externalising ‘problem' activities does not constitute facing and understanding the issue underneath the problem. All of the outsourcing decisions had been made at a very senior level in the organisation. In two cases, a 'make' or 'buy' committee was formed and in another case, where insufficient internal capacity was the driver, the in-house function had made the decision. The following questions were centred on the involvement of the in-house provider in the process and how their costs were calculated:

\begin{tabular}{|c|c|c|}
\hline Questions & Answers & \\
\hline $\begin{array}{l}\text { Were the in-house providers aware of the possibility } \\
\text { that their activity was being considered for outsourcing? }\end{array}$ & $\begin{array}{l}\text { Yes } \\
\text { No }\end{array}$ & $\begin{array}{l}83 \% \\
17 \%\end{array}$ \\
\hline At what stage? & $\begin{array}{l}\text { From outset } \\
\text { at implementation }\end{array}$ & $\begin{array}{l}66 \% \\
34 \%\end{array}$ \\
\hline $\begin{array}{l}\text { Were there any other options available than } \\
\text { outsourcing? }\end{array}$ & $\begin{array}{l}\text { No } \\
\text { Yes, but not } \\
\text { seriously considered }\end{array}$ & $\begin{array}{l}66 \% \\
34 \%\end{array}$ \\
\hline $\begin{array}{l}\text { Was the in-house provider issued the same tender } \\
\text { document as the potential supplier? }\end{array}$ & $\begin{array}{l}\text { No } \\
\text { Yes }\end{array}$ & $\begin{array}{l}83 \% \\
17 \%\end{array}$ \\
\hline
\end{tabular}

These results seen together paint an interesting picture. It shows that whilst the in-house providers were aware in the majority of cases that their activity was a candidate for outsourcing, they were by and large powerless to do anything about it as they were not given the opportunity to participate in the tendering process. Alexander and Young (1996b) suggest that giving in-house providers the opportunity to bid on an equal 
footing with external providers can lead to the in-house function improving significantly. It could be further argued that in-house functions in all but a few instances have significant benefits that an external provider has not, namely, locality, and an understanding of company procedures, culture and practice. These factors represent a risk when dealing with any outside provider and should be taken into account. Excluding the in-house provider from the outsourcing decision process could have demotivating ramifications on the particular function but also on the whole organisation as a feeling of 'corporate edict' could pervade. The second finding is:

In-house functions are rarely provided the same tender document as the outside provider and are consequently not compared on an equal footing.

All but one of the firms interviewed conducted a detailed analysis of the in-house costs remotely. There was, however, an equal split between organisations that were and were not factoring in the cost of managing the outsourced operation. These results were particularly interesting as, in addition to the major finding already highlighted, it suggested that in all too many cases the appropriation of costs was insufficient to present an accurate portrayal of the actual cost of outsourcing.

\section{$\underline{\text { Post-outsourcing Measurement }}$}

Interviewees were asked how the outsourced activity was measured. The scope of measurement varied greatly with a distinct correlation between the size of the organisation and the sophistication of the measurements employed. In general the smaller firms were measuring absolutes like on-time delivery, levels of rework (quality control) and lead-time. They were either identical measures or slight variations on their standard vendor management program, which applied to all incoming purchased goods. 
None of the smaller organisations were extending their measurements to encompass more esoteric service metrics like, relationships, and supplier flexibility or added value solutions. Furthermore there was no end-user feedback incorporated into the process. These findings were expected and overall the measurements were quite adequate for the activities being outsourced, as they tended to have single contact points within the host organisation and were straightforward in nature.

For the larger organisations and particularly in cases where the internal customer base was extensive, the levels of measurement were quite sophisticated. They were operating supplier rating programs which assessed a wide variety of factors, and in one case in particular, a bespoke supplier assessment program was in operation. Overall supplier measurement was being conducted and varied from one company who had a bespoke program that extended as far as end-user attitude surveys to a firm, at the other end of the spectrum, who measured delivery, quality and lead-time. In all but one case this was an ongoing process with a small number conducting formal reviews on regular intervals (monthly, quarterly or half yearly),

The more interesting finding came in response to the setting of improvement targets and benchmarking. Only half of the organisations interviewed were setting any form of improvement targets for the supplier, and only one company was conducting benchmarking exercises on an ongoing basis. These responses have important implications for both the supplier and customer:

- For the supplier, the absence of any improvement targets could result in the supplier recouping all the surplus value that both parties may generate. Whether they are 
aware or not that a benchmarking process is in operation, there is a risk that his control relative to the customer may increase over time.

- For the customer, the absence of any improvement targets may mean that potential savings are not being realised and the competitiveness of the outsourcing venture may gradually diminish in relation to the market.

Whilst the responses were split over improvement targets and as such no conclusions can be drawn, the absence of any supplier benchmarking could be leaving the customers unnecessarily exposed. It should be noted that supplier benchmarking is not the only method for establishing the ongoing viability of a supplier relationship, but it is an effective measure to proactively assess overall competitiveness and will desist more reactive approaches. Another question asked was whether the in-house activity was measured in the same way as the outsourced activity. Once again the majority of responses was that they were not, with only one organisation stating that they were measured in the same way. This could serve to endorse the previous findings but could also indicate that outsourcing had been the catalyst for more detailed business measurement.

\section{CONCLUSIONS}

The purpose of this paper is to present an empirical research on outsourcing in 14 British companies, focusing on two key areas: pre-outsourcing decision process and post-outsourcing supplier management. The research shows that cost analysis is rarely performed on an equal footing. Costs for the in-house provider are usually assessed by a third party and then compared with the results of the external provider's quotations. This method overlooks the fact that the in-house provider may be in a position to change in accordance with the requirements of the tender document and often will have 
significant benefits over externalising the activity. It is recommended that an alternative approach should be adopted in order to present a more representative picture. The proposal is that the in-house provider is counselled prior to any tendering process and is made aware that their function is being considered for outsourcing. They should be provided with the same tender document as the external provider and given the opportunity to bid, and encouraged to make any recommendations that would improve their overall competitiveness against the external bids. The rationale for this approach is that only through operating in this way can the in-house provider be assessed on what they could achieve rather than what they had achieved prior to the decision to outsource.

Another recommendation to improve the overall objectivity relates to measurement. In many of the cases studied, the performance of the external provider was measured completely differently to the in-house provider; indeed in some cases, the in-house providers were not measured at all. The proposal is that a set of in-house measures is put into operation for a period of time (say, six to twelve months) prior to the tendering process which would be the same as those employed if the activity were outsourced. The tender document should then include that set of measures for comparison between in-house and external provider. This serves two purposes. First, it ensures a fair comparative assessment is made before any decision to outsource; and secondly, if the activity is to be outsourced, it is measured against the performance of the original inhouse provider. These would help to ensure that a true assessment of supplier performance is made. The next recommendation relates to objective candidate selection. The research found too many cases of decisions to outsource being made and a business 
case then fitted around that decision. This could point to one of the main reasons why outsourcing expectations are not being met by so many. The selection of outsourcing candidates does not represent a decision to outsource but a decision to perform further analysis. There may be good reasons why the candidate has been selected but the business justification should be the deciding factor. This is a mind-set issue and is vitally important for ensuring objectivity.

There are two recommendations in terms of post-outsourcing supplier management. Whilst there were a few cases of comprehensive ongoing performance management, most were managing their outsourcing program in the same way as their standard supplier management procedure. Outsourcing deals, whether they are secondary or primary activities, are worthy of a bespoke measurement and management system. Performance management should include regular formal business review meetings. These meetings should cover the following areas: 1) business overview by both parties; 2) performance review of preceding period and any corrective actions if needed; 3) new targets for next period. The objective should be to continually review and re-set targets in an effort in sustaining competitive advantages. Some kind of reward-based approach may also be appropriate to encourage optimum supplier performance but would depend on the nature of the outsourced activity. An open co-operative relationship should be encouraged.

The second point is benchmarking. This should be performed on a regular basis and involves the re-tendering of the outsourced activity to other providers. The results of this activity serve to calibrate the existing provider's performance and offers avenues 
for improving their performance. Whether the supplier is made aware of this process explicitly or implicitly would depend on the situation, but either way the supplier should be aware that they are being regularly assessed against the best performance in their sector. This will help to sustain long-term competitive advantage.

As a final remark, findings from this research should be treated with some caution because it was based on a small sample. More research is need to match the dramatic growth in the outsourcing field. There are large number of topics for further investigation, to name a few:

1. Does outsourcing really create value (Bruce and Useem, 1998)? If yes, how to measure it?

2. How can outsourced activities be integrated into the firm's value chain to maintain competitive advantages?

3. What are the possible influences of outsourcing ventures on the firm's structure, culture and staff's attitude? 


\section{References}

Alexander, M. and Young, D. (1996, a), "Strategic Outsourcing", Long Range Planning, 29:1, 116-9.

Alexander, M. and Young, D. (1996, b), “Outsourcing: Where’s the Value?”, Long Range Planning, 29:5, 728-30.

Bettis, R., Bredley, S. and Hamel, G. (1992), "Outsourcing and Industrial Decline”, Academy of Management Executive, 6, 7-22.

Brown, M. (1997), “Outsourcing”, Management Today, Jan. 56-60.

Bryce, D. J. and Useem, M. (1998) “The Impact of Corporate Outsourcing on Company

Value”, European Management Journal, 16:6, 635-43.

Greenberg, E. R. and Canzoneri, C. (1997), Outsourcing: the AMA Survey, American Management Association, New York.

Lacity, M. C. and Hirschheim, R., and Willcocks, L. (1994), "Realising Outsourcing Expectations: Incredible Expectations, Credible Outcomes", Journal of Information Systems Management, 11, 7-18.

Kavanagh, J. (1997), “Trend towards Contracting-out”, the Financial Times, 4 June. PA Consulting Group, (1996), Management Summary -International Strategic Sourcing Survey.

Quinn, J. B. and Himmer, F.(1994), “Strategic Outsourcing”, Sloan Management Review, Summer, 43-55.

Summer, D. (1997), “Outsourcing - Driven by Finance”, the Economist, 11 Jan. p27. Walker, G. and Weber, D. (1984), “A Transaction Cost Approach to Make-or-Buy Decisions”, Administrative Sciences Quarterly, 29, 373-91. 